\title{
PENERAPAN CUSTOMER RELATIONSHIP MANAGEMEN CRM) PADA TOKO SOUVENIR MITRA AGUNG UTAMA
}

\author{
Willy Andel Elimª, Mardhalia Saitakela \\ ${ }^{a . b}$ Sekolah Tinggi Manajemen Informatika Komputer (STIKOM) Uyelindo Kupang \\ $\underline{\text { aelim willy21@yahoo.com }}, \underline{\text { bmardhaliasaitakela@gmail.com }}$
}

\begin{abstract}
ABSTRAK
Toko Souvenir Mitra Agung Utama merupakan sebuah usaha yang bergerak dalam bidang penjualan souvenir khas Nusa Tenggara Timur. Peminat produk dari toko ini berasal dari berbagai macam kalangan bahkan orang asing yang meminati produk-produk dari toko ini. Masalah yang dihadapi oleh pemilik usaha adalah belum adanya sistem yang terkomputerisasi dalam merekap data penjualan, belum adanya pencatatan informasi pelanggan sehingga pihak Toko kesulitan dalam memberikan layanan khusus untuk pelanggan, Pengelolaan komplain juga masih belum sepenuhnya ditangani dengan tepat, target pemasaran masih terbatas karena pemasaran masih dilakukan secara langsung dengan pelanggan datang ke toko. Tujuan Penelitian ini adalah untuk menerapkan sistem berbasis website dengan konsep customer relationship management (CRM) untuk mempertahankan loyalitas pelanggan melalui hubungan yang erat dan terbuka agar adanya komunikasi dua arah antara Toko Mitra Agung Utama dan pelanggan. Penelitian ini menggunakan metode studi literatur, observasi dan wawancara untuk mendapatkan data-data dan informasi terkait. Hasil dari penelitian ini adalah sebuah sistem berbasis website dengan penerapan customer relationship management dengan Fungsi-fungsi sistem meliputi pengelolaan data barang, perekapan data penjualan, pendataan informasi pelanggan, promosi barang dengan menggunakan data dan informasi pelanggan, pemesanan barang dan pemberian saran oleh pelanggan terhadap produk dan pelayanan dari Toko Mitra Agung Utama.
\end{abstract}

Kata kunci: CRM, Loyalitas Pelanggan, Toko Souvenir Mitra Agung Utama.

\begin{abstract}
Mitra Agung Agung Souvenir Shop is a business that is engaged in selling souvenirs typical of East Nusa Tenggara. Product enthusiasts from this shop come from various circles and even foreigners who are interested in the products of this store. Problems faced by business owners are the absence of a computerized system in recapitulating sales data, the absence of recording customer information so that the Stores have difficulty in providing special services for customers, the management of complaints is still not fully handled properly, marketing targets are still limited because marketing is still done directly with customers coming to the store. The purpose of this study is to implement a website-based system with the concept of customer relationship management (CRM) to maintain customer loyalty through a close and open relationship so that there is a two-way communication between Mitra Agung Utama Stores and customers. This study uses literature study, observation and interview methods to obtain data and related information. The results of this study are a website-based system with the application of customer relationship management with system functions including managing data items, recording sales data, collecting customer information, promoting goods using customer data and information, ordering goods and giving advice by customers to products and services from the Mitra Agung Utama Shop.
\end{abstract}

Keywords: CRM, Customer Loyalty, Mitra Utama Agung Souvenir Shop 


\section{PENDAhUluan}

Mitra Agung Utama merupakan Toko yang menjual souvenir dari berbagai macam daerah di Nusa Tenggara Timur, seperti kain tenun berupa sarung, selendang dan selimut. Produk-produk lain berupa tas, dompet, patung dan alat musik. Usaha penjualan souvenir ini sudah dimulai dari 20 tahun yang lalu sehingga toko ini sudah banyak dikenal masyarakat Kota Kupang. Toko ini memiliki banyak pelanggan dari berbagai kalangan bahkan orang asing yang datang ke Kota Kupang sering membeli souvenir khas NTT di tempat ini. Lokasi toko yang berada di dekat jalan utama wilayah Naikoten 1 yang merupakan keuntungan bagi Toko Mitra Agung Utama. produk yang paling banyak diminati oleh para pelanggan dari Toko ini adalah kain tenun jenis sotis yang berasal dari Sabu, Rote dan Timor Tengah Utara dengan harga yang lebih terjangkau yaitu harga 500.000 rupiah hingga mencapai 1.000 .000 rupiah. Keuntungan lebih didapat dua kali lipat pada bulan-bulan tertentu seperti bulan desember. Walaupun sudah 20 tahun bisnis ini dijalankan, toko ini belum memiliki sistem yang terkomputerisasi dan membuat toko ini masih menggunakan buku untuk merekap seluruh data penjualannya sehingga pencatatan data penjualannya belum seutuhnya dikelola dengan baik. Belum adanya pencatatan informasi pelanggan yang membuat pihak toko kesulitan dalam memberikan layanan khusus berupa promosi, diskon atau pemotongan harga. Pengelolaan komplain juga masih belum sepenuhnya ditangani dengan tepat, tidak adanya pencatatan keluhan pelanggan yang dapat menyebabkan kesalahan dalam mengelola dan mengatasi keluhan pelanggan sehingga dampaknya dapat membuat citra toko menjadi buruk. Kekecewaan pelanggan akan hal ini dapat membuat para pelanggan berpindah ke produk dari toko lain. Untuk mengatasi masalah tersebut, maka dibutuhkan sebuah sistem dengan penerapan konsep Customer Relationship Management.

Dengan menerapkan sistem CRM dapat menarik minat pelanggan baru di samping tetap memelihara tingkat kepuasan pelanggan yang telah ada [1]. Keuntungan Penggunaan CRM adalah servis yang lebih cepat, mengurangi harga, memperbesar keuntungan, mempunyai rasa memiliki, meningkatkan koordinasi tim, tingkat kepuasan pelanggan menjadi lebih tinggi, meningkatkan loyalitas pelanggan [2]. Sistem ini dapat membantu pihak dari Toko Mitra Agung Utama dalam mengelola data dan informasi pelanggan, data hasil penjualan, mempromosikan barang dengan memanfaatkan data dan informasi yang ada pada pelanggan, dapat membantu pelanggan dalam memesan produk tanpa harus mendatangi lokasi dan memberikan masukan terhadap produk serta pelayanannya. Dengan data dan informasi pelanggan Toko Mitra Agung Utama dapat mempertahankan kesetiaan pelanggannya diantaranya terdapat promosi dan pemotongan harga produk apabila pelanggan toko membeli produk dalam jumlah yang banyak dan juga toko memberikan petunjuk bagaimana cara merawat produk yang tergolong rapuh (fragile). Petunjuk perawatan tersebut biasanya terdapat pada produk berupa kain tenun, sarung yang diperlukan ketelitian dalam merawatnya. Contohnya kain tenun yang warna gampang pudar apabila cara mencucinya salah. Kemasan yang dipakai untuk mempacking barang-barang yang akan dibeli oleh pelanggan juga didesain dengan bagus untuk menarik perhatian pelanggan. Sistem yang dibangun juga terhubung dengan menggunakan media sosial. 


\section{METODE PENELITIAN}

a. Pengumpulan data yang dilakukan dalam penelitian yaitu :

1. Observasi Proses pengumpulan datadata dan informasi, dilakukan dengan cara pengamatan secara langsung terhadap objek penelitian pada Toko Souvenir Mitra Agung Utama.

2. Wawancara Proses pengumpulan data-data dan informasi juga dilakukan dengan mengadakan wawancara secara langsung dengan pemilik Toko Souvenir Mitra Agung Utama.

b. Flowchart Sistem

Flowchart Sistem merupakan bagan yang menunjukkan alur kerja atau apa yang sedang dikerjakan di dalam sistem secara keseluruhan dan menjelaskan urutan dari prosedur-prosedur yang ada di dalam sistem [3], yang dapat dilihat pada gambar 1 dan 2 sebagai berikut.

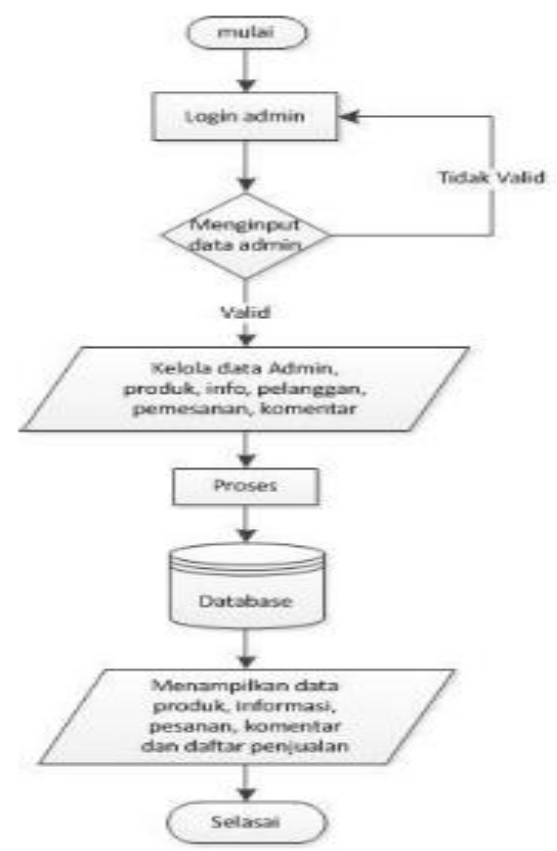

Gambar 1. Flowchart sistem pada admin

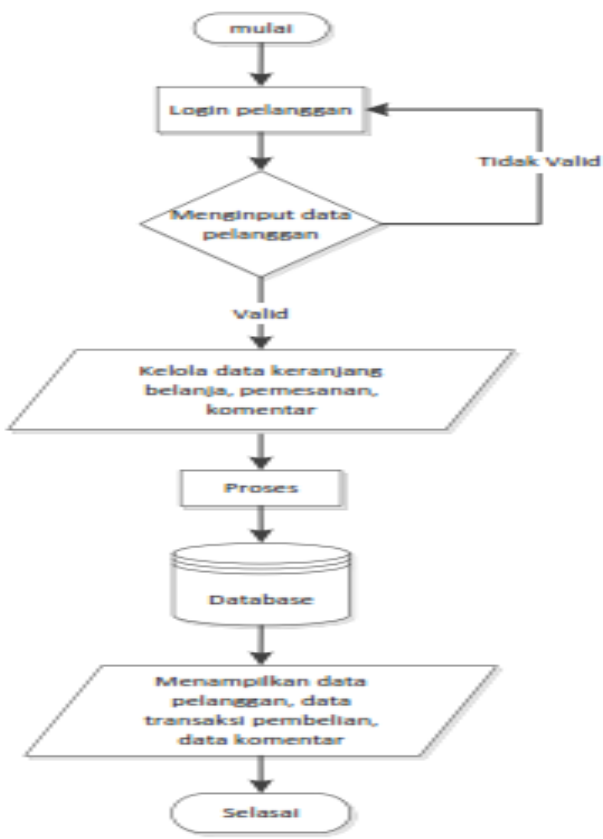

Gambar

2. Flowchart sistem pada pelanggan

c. Use case diagram

Use case diagram adalah diagram yang menampilkan hubungan antara aktor dengan use case [4]. Use case digunakan untuk menunjukkan hubungan antara aktor sebagai pengguna sistem dengan use case yang digunakan.

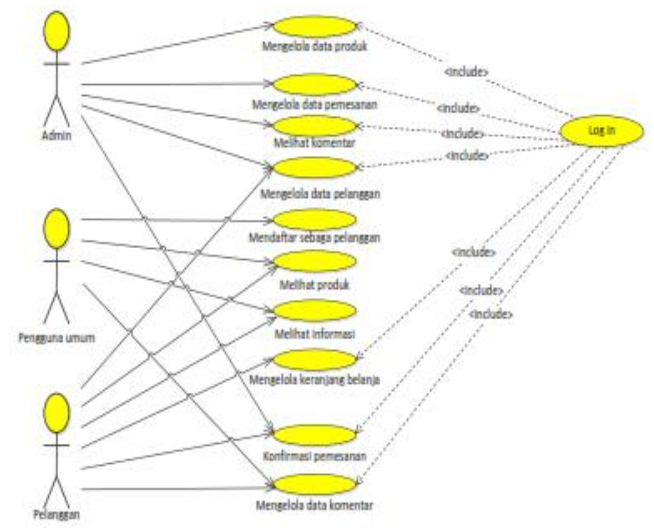

Gambar 3. Use Case Diagram pada Toko Souvenir Mitra Agung Utama. 


\section{HASIL DAN PEMBAHASAN}

a. Tampilan menu utama

Halaman utama dari website Mitra Agung Utama Store terdiri dari menu Home, Menu Produk, Menu Testimoni, Menu Daftar, Menu keranjang (dalam bentuk ikon keranjang) dan menu Login. Dalam halaman ini tersedia fitur CRM berupa notifikasi rekomendasi produk terbaru dan rekomendasi produk yang paling diminati.

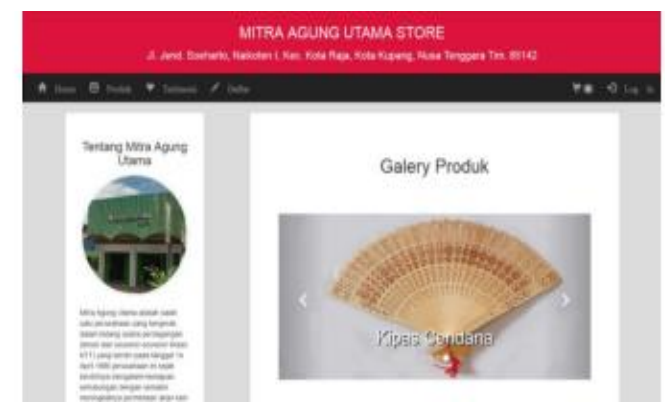

Gambar 4. Tampilan menu utama

b. Tampilan halaman pendaftaran pelanggan.

Halaman pendaftaran pelanggan ini $u$ ser dapat mendaftar untuk menjadi pelanggan sehingga user dapat mengakses website Mitra Agung Utama Store dengan mudah.

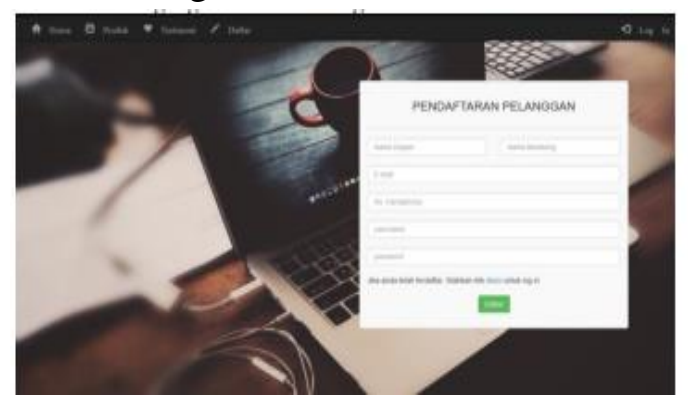

Gambar 5. Tampilan halaman pendaftaran pelanggan c. Tampilan halaman produk

Halaman produk berisikan informasi produk-produk yang dijual kepada pelanggan. Pada halaman ini, pelanggan dapat memilih produk berdasarkan kategori-kategori produk, pelanggan dapat melakukan pencarian produk melalui fitur pencarian produk.

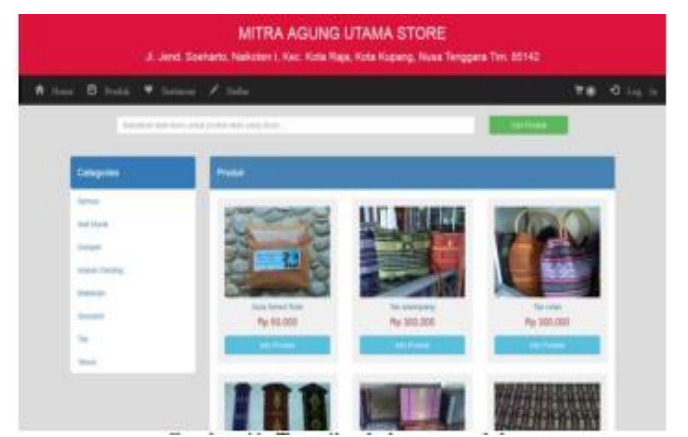

Gambar 6. Tampilan halaman produk

d. Tampilan halaman info produk.

Halaman info produk adalah halaman yang berisikan tentang informasi lengkap dari suatu produk. halaman ini dapat diakses dengan cara memilih button info produk pada salah satu produk yang ada di halaman produk. Pada halaman ini, pelanggan juga dapat langsung memesan produk.

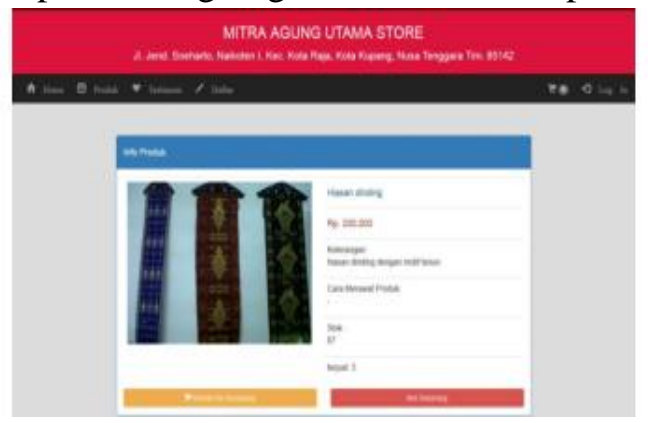

Gambar 7. Tampilan halaman info produk

e. Tampilan halaman detail pemesanan Pada halaman detail pemesanan, hasil pesanan yang telah dibuat oleh pelanggan akan ditampilkan di halaman ini. 

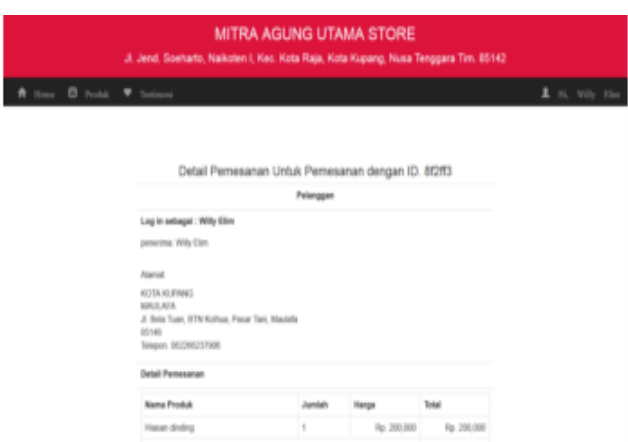

Gambar 8. Tampilan halaman detail pemesanan

f. Tampilan halaman pembayaran

Pada halaman pembayaran, pelanggan akan diberikan informasi mengenai pembayaran berupa nominal yang harus dikirimkan, bank, nomor rekening, nama pemilik rekening dan batas waktu pengiriman.

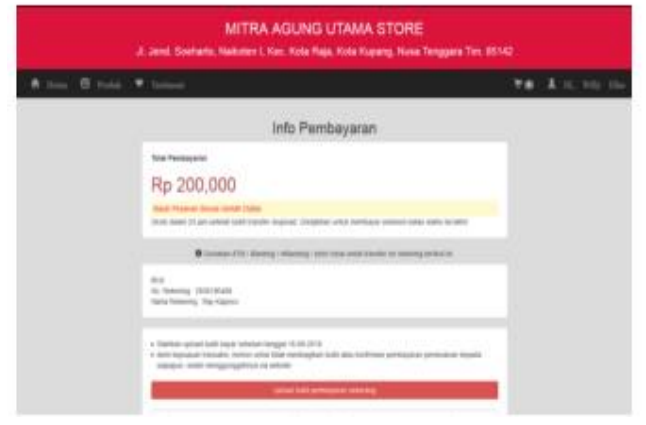

Gambar 9. Tampilan halaman pembayaran

g. Tampilan halaman daftar riwayat pemesanan

Halaman daftar pemesanan adalah halaman yang menampilkan riwayat daftar pemesanan yang dilakukan pelanggan. Pada halaman ini pelanngan dapat melihat rincian pemesanan, mengupload bukti pembayaran dalam bentuk file PEG dan membatalkan pemesanan.

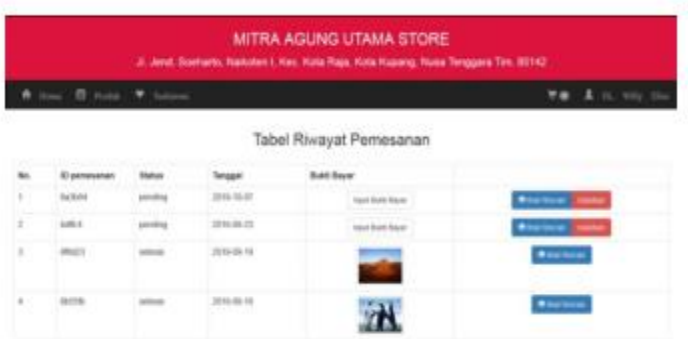

Gambar 10. Tampilan halaman daftar riwayat pemesanan

h. Tampilan halaman analisis CRM

Halaman analisa CRM adalah halaman yang digunakan oleh admin dalam menganalisa CRM untuk menentukan promo. Pada halaman ini admin harus menentukan tanggal penjualan pada bulan sebelumnya agar website dapat menampilkan riwayat penjualan pada bulan sebelumnya sehingga admin dapat menentukan promo pada produk dalam bentuk potongan harga.

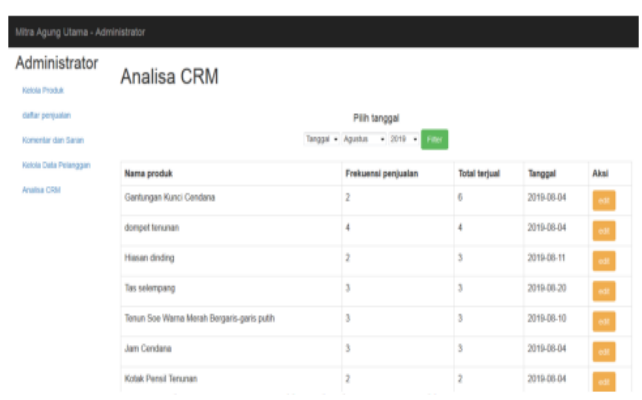

Gambar 11. Tampilan halaman analisis CRM

i. Tampilan halaman login admin

Halaman login admin adalah halaman yang digunakan oleh admin untuk memverifikasi data admin agar admin mendapatkan hak akses sepenuhnya dalam mengolah data-data dalam halaman admin. 
Gambar 12. Tampilan halaman login admin

j. Tampilan halaman daftar riwayat pesanan Halaman daftar riwayat pesanan adalah halaman yang digunakan admin untuk melihat data pesanan, mengkonfirmasi status pesanan dan membuat laporan penjualan. Jika pelanggan telah melunasi pembayaran maka admin akan mengkonfirmasi bahwa status pesanan telah selesai dan admin dapat mencetak laporan penjualan untuk pengarsipan

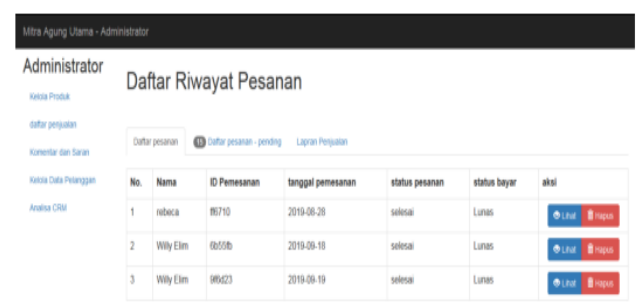

Gambar 13. Tampilan halaman daftar riwayat pesanan

\section{KESIMPULAN}

Dengan menerapkan sistem berbasis website dengan konsep customer relationship management (CRM) pada Toko Mitra Agung Utama dapat mempertahankan loyalitas pelanggan melalui hubungan yang erat dan terbuka agar adanya komunikasi dua arah antara Toko Mitra Agung Utama dan pelanggan.

\section{DAFTAR PUSTAKA}

[1] Kalakota, R \& Robinson, Marcia. (2001). "e-Business 2.0 roadmap for success", Massachusetts: Addsion Wesley Longman Inc.

[2] Lawson et al. (2004). The Impact of Customer Relationship Management on Customer Loyalty: The Moderating Role of Web Site Characteristics. Journal of Computer-Mediated Communication

[3] Indrajani, S. M. (2011). Pengantar dan Sistem Basis Data. Jakarta: PT Elex Media Komputindo.

[4] Sugiarti Yuni, S.T., M.Kom. 2013, Analisis dan Perancangan UML (Unified Modelling Language) Generated VB.6, Graha Ilmu, Yogyakarta 